\title{
Brigitte Schroeder-Gudehus e Anne Rasmussen. Les fastes du progrès: le guide des Expositions universelles 1851-1992. Paris, Flammarion, 1992
}

\author{
Resenha por Heloisa Barbuy \\ MP/Universidade de São Paulo
}

Antes de tecermos qualquer comentário crítico sobre a obra em questão, é preciso esboçar o panorama bibliográfico no qual ela se insere. Só assim será possivel avaliar o significado de sua contribuição.

As obras de caráter geral sobre as exposições universais são relativamente escassas. A própria publicação de que vamos tratar dá uma idéia da limitação existente ao enumerar não mais do que trinta e seis fítulos na categoria de "estudos gerais" sobre o assunto (p. 232-233).

Entretanto, embora o número seja ainda pequeno, percebe-se um interesse cada vez maior pelas exposições quando se constata que destas trinta e seis publicações (que abrangem fítulos desde a década de 1930), dezoito são posteriores a 1980.

Ocorre que, dentro deste quadro, são poucas as obras de natureza realmente analítica. A maior parte é descritiva, servindo mais como fonte de informações do que como elemento para discussão teórica.

No que diz respeito aos estudos monográficos, a produção é bem maior pois muitos pesquisadores costumam se dedicar a apenas uma exposição, a um só aspecto das exposições, à participação de uma dada nação ou ao conjunto de exposições havidas em um determinado país ou cidade. Mas é verdade que, muitas vezes, as monografias acabam trazendo considerações gerais, importantes para a compreensão do fenômeno das exposições universais como um todo.

Especialmente nos Estados Unidos e na França los dois países que organizaram maior número de exposições universais), aumenta a quantidade de publicações sobre o assunto. Também no Brasil há muitas pesquisas em 
* Brigitte Schroeder-Gudehus é professora no Departamento de Ciência Política da Universidade de Montreal e Anne Rasmussen é professora na Universidade de Paris X. Desenvolveram esta obra como pesquisadoras do Centro de Pesquisas de História das Ciências e Técnicas da Cidade das Ciências e da Indústria de Paris. desenvolvimento, como atesta o recente seminário organizado pelo Instituto Brasileiro do Patrimônio Cultural, no Museu Imperial de Petrópolis (Lições das coisas: o universo das exposições do século XIX ao XX, maio/93).

Dos autores nacionais, citaríamos Francisco Foot Hardman, Margarida de Souza Neves, Margareth Campos da Silva Pereira, Maria Inez Turazzi e Sandra Jatahy Pesavento, entre outros.

Nos Estados Unidos, desde o início da década de 1980, três autores se destacam no que diz respeito às exposições americanas: Burt Benedict, Paul Greenhalgh e Robert Rydell, que expressam as tendências, nos meios acadêmicos americanos, para a interpretação das exposições universais (ou melhor, das World's Fairs americanas) nas linhas da história da ideologia e da antropologia histórica.

No caso da França, desde o final da década de 1970, a aproximação do bicentenário da Revolução Francesa, do centenário da Exposição Universal de 1889 (comemorativa da Revolução) e a idéia - depois abandonada - de uma outra exposição universal em Paris, em 1989, provocaram a intensificação de estudos em torno das exposições universais. E, também, a organização, por grandes museus, de exposições em torno do tema.

Panoramas das exposições universais são apresentados por Pascal Ory e por publicações de vários outros autores, reunidas em catálogos de exposiçōes do Museu de Artes Decorativas e do Museu de Orsay (Paris). A veiculação de abundante iconografia é a marca comum a estas obras, preocupadas em possibilitar ao leitor (ou observador), uma visualização das exposições. Parecem ter sempre uma meta subiacente: fazer reviver, cem anos depois, a euforia e o imaginário das exposiçōes do século XIX. São sintéticas, frequentemente em estilo de crônicas, repletas de iconografia, e cumprem o objetivo de recolocar na paufa o tema das exposições universais.

Como publicação de natureza mais acadêmica, destaca-se um número especial da revista le mouvement social (n. 149, 1989), organizado por Madeleine Rebérioux, sob o título "Mise en scène et vulgarisation à 'Exposition universelle de 1889". Autora de artigos importantes sobre as exposições francesas da segunda metade do século XIX, RebériouX estrutura em. quatro partes este campo de estudos: quanto às intenções de seus organizadores, aos confrontos ideológicos, à organização espacial e às reações do(s) público(s).

Tendendo, de início, ela própria, mais para o estudo da situação operária nas exposições, tanto no canteiro de obras como na condição de público, inclina-se cada vez mais para o campo do imaginário da História da Cultura.

Rebérioux coordenou, durante vários anos, seminários sobre o tema na Ecole des Hautes Etudes, em associação com as Universidades de Paris VIII e Paris I. Destes seminários derivaram várias teses e algumas publicações. A razão mais direta pela qual os estamos mencionando é o fato de que em 1992, ano da Exposição Universal de Sevilha, e após muito tempo de pesquisa, duas de suas antigas alunas, Brigitte Schroeder-Gudehus e Anne Rasmussen *, publicam, em co-autoria, Les fastes du progrès: le guide des expositions universelles 1851-1992. 
Matéria prima inesgotável para pesquisas nas mais variadas áreas, as exposições universais apresentam aos interessados uma situação paradoxal: um universo quase ilimitado de documentação textual e iconográfica lque prenuncia grandes possibilidades para o pesquisador) e uma quase incontornável dispersão desta documentação por demasiadas instituições e por vários países, decorrente da própria natureza múltipla e internacional das exposições.

Foi com esta dificuldade que se depararam Schroeder-Gudehus e Rasmussen, conforme relatam no prefácio de sua obra. Visando, inicialmente, pesquisar a formação e a difusão das representações científicas e técnicas nas exposições universais, logo se deram conta das dificuldades que teriam em localizar a documentação necessária. Decidiram, então, tomar para si a tarefa de sistematização de dados e referências documentais sobre vinte e nove exposições, realizadas entre 1851 e 1992.

Tendo feito este árduo trabalho, sua obra torna-se referência indispensável para estudiosos do tema, que passam a contar com informações precisas sobre cada exposição, nas fichas sinaléticas que compõem mais de dois terços da publicação (p.57-231). Assim, a obra constitui-se, como diz seu subtítulo, num guia das exposições universais.

Os ítens relativos a cada exposição referem-se a: designação oficial, tema, símbolo, atrações ou realizações arquitetônicas, cátegoria, localização, datas, superfície, expositores, visitantes, preço de entrada, custo, etapas, forma jurídica e modo de funcionamento, organização de responsabilidades, participação estrangeira, edifícios e pavilhões, classificação, congressos, sistemas de júris e recompensas e indicações bibliográficas .

As exposições universais, pela vibração literalmente espetacular que denotam sob o ponto de vista do público e pela nitidez doutrinária que revelam sob o ponto de vista dos organizadores, são mais comumente abordadas sob estes dois prismas. Schroeder-Gudehus e Rasmussen fogem à regra. Mesmo não pretendendo oferecer uma obra teórica mas sobretudo um instrumento de pesquisa, as autoras dão também um outro tipo de contribuição importante ao fazerem abordagens novas do assunto: cada uma assina um capítulo, referindose, segundo elas próprias, à "ordem externa" (história da regulamentação internacional) e à "ordem interna" (história das classificações) das exposições (p.3).

No que tange à "ordem externa", Schroeder-Gudehus (em co-autoria com A. Bzderal, enfrenta a questão das exposições como empreendimentos econômico-financeiros no capítulo dedicado à "regulamentação internacional das exposições" (p.39-55). Trata-se de um histórico das relações internacionais em torno da organização das exposições universais. Aborda as exposiçōes sobretudo do ponto de vista dos organizadores (Estado e iniciativa privada), mas de maneira bastante pragmática, revelando-as como grandes empreendimentos que envolvem somas vultosas de aplicações financeiras e têm em vista retornos tanto de capital como de imagem (de empresas e de nações). O capítulo oferece inumeráveis informações, esclarecendo as funções que as exposições universais sempre tiveram de propagandistas do Estado e/ou dos expositores privados. E como as relações entre estes e aquele se dão ao longo do tempo ou especificamente, em alguns países. (França, Alemanha, Inglaterra), 
no mais das vezes configurando-se uma fusão de interesses econômicos, públicos e privados, em torno das exposições.

No que se refere à "ordem interna", Rasmussen se dedica ao problema das "classificações de exposição universal" (p.21-38), apresentando confribuição de péso, por abordar questões essenciais de forma direta e articulada. Trabalha as classificações em seu sentido mais objetivo dentro das exposições, isto é, o da divisão por classes e grupos prevista em regulamentação escrita a ser seguida pelos expositores. Tais classificações dizem respeito a produtos brutos e indústrias extrativas (como ferro e metalurgia), a produtos manufaturados (como tecidos, roupas, móveis), a indústrias em geral (como a mecânica, a elétrical, a obras de arte e também a outras categorias, conforme a exposição (como as classes de produtos agrícolas, que surgem em 1867; atividades de ensino técnico, em 1878; economia social, em 1889). As questões apontadas por Rasmussen, que consideramos essenciais estão inseridas na discussão que se desenvolverá nas próximas linhas.

A obra de Schroeder-Gudehus e Rasmussen aborda duas questões cuja discussão é fundamental como ponto de partida para qualquer pesquisa histórica sobre as exposições universais. A primeira refere-se à periodização e às noções de mudanças e permanências; a segunda é a questão, acima mencionada, das classificações (Rasmussen), base metodológica da própria organização das exposições, que como tal traz inúmeras consequências.

As exposições universais surgem lainda não com esta denominação mas já com os propósitos universalistas que as marcariam), em Londres, no ano de 1851, com a Great Exhibition of the Works of Industry of All Nations. Concebidas, em princípio, como exposições industriais e comerciais e com pretensões enciclopédicas de abrangência, guardam estas características por toda a segunda metade do século XIX e até o início da Primeira Guerra Mundial, quando se realizou a exposição internacional de San Francisco (1915).

O estabelecimento deste período (1851-1915), como correspondente a uma primeira fase do fenômeno, parece unânime entre os relativamente poucos autores que tratam do assunto e é também assumido por SchroederGudehus e Rasmussen: a Primeira Guerra Mundial corresponde a um momento de ruptura, que tem suas implicações também sobre o próprio conceito de exposição universal.

Organizando os dados sobre cada uma das exposições universais (1851-1992), as autoras propõem-se possibilitar o estudo das mudanças e das permanências nas exposições universais (p.5). Elas próprias avançam por este caminho, na primeira parte da obra, não deixando dúvidas quanto às mudanças de sentido e à diminuição do poder de difusão das exposições, que se dão a partir da Primeira Guerra.

Tornam mais clara e direta a idéia de que, em razão das mudanças na sociedade, que, culminaram na Primeira Guerra-Mundial, e dos limites que estas mudanças impõem à crença na ideologia do progresso (que se pode dizer absoluta nas mentalidades burguesas ocidentais do século X|X|, as exposições perdem seu caráter essencialmente industrial-comercial e seus anseios universalistas. Tornam-se mais especializadas (após a Primeira Guerra) e 
com contornos aparentemente mais humanistas (como ocorre atualmente) (Rasmussen, p. 35).

Quanto a seu poder de difusão, diminui proporcionalmente ao desenvolvimento e diversificação dos fenômenos de massa, dos quais são uma das primeiras manifestações. $\hat{E}$ importante ter claro que as primeiras exposições universais do século XIX ocorrem justamente numa época pré-cinema, pré-rádio, pré-televisão, em que a fotografia, o fonógrafo e o telefone são novidades, em que as viagens são demoradas e difíceis. E também que as próprias novidades tecnológicas - as máquinas e os inventos - são frequentemente apresentadas ao mundo durante as exposições. Estas são, assim, um veículo de comunicação de massa avant la lettre. É neste sentido que as autoras assinalam que, atualmente, as exposições não podem mais ter o mesmo papel que tinham nos imaginários do século XIX, quando apenas elas tinham poder de difusão em massa: "as funções privilegiadas que exerciam para seus visitantes, a informação, a instrução, o estranhamento, sofrem hoje a concorrência de múltiplas instâncias voltadas especialmente para cada um desses objetivos" (p.5).

A bibliografia muitas vezes fala nas exposições deste primeiro período (1851-1915) como sendo todas similares. Isto não parece impróprio quando o que se quer é explicar o significado essencial de um processo de que cada uma faz parte. Mas em seu prefácio, Schroeder-Gudehus e Rasmussen lamentam que os poucos estudos analíticos sobre as exposições universais "nem sempre tenham conseguido evitar a criação de arquétipos de exposição universal, a partir de partis pris nacionais ou disciplinares, que encontram sua origem na indiferença em relação a informações sobre outras exposições" (p.3).

Mas como evitar o arquétipo (e por quel se da própria leitura da obra dessas autoras, o que fica mais claro é justamente que, em relação às exposições, universais, as permanências são mais marcantes do que as mudanças? É claro que no estudo de cada uma delas, há que se levar em conta sua historicidade, isto é, contextos de tempo e espaço - e aquilo que são suas respectivas peculiaridades. Mas para a compreensão do fénômeno, ao menos em relação à primeira fase (1851-1915), em muitos pontos de vista pensamos mesmo que se possa falar em arquétipo de exposições universais: enquanto estruturas expositivas - materialmente construídas e visualmente apreensíveis - constituem-se em veículos didáticos para instruir (ou industriar) as massas sobre a praxis da sociedade industrial (um modelo, um dever-ser de ordem social).

Basta ver que em sua argumentação para demonstrar algumas das mudanças ocorridas, mesmo na longa duração do período compreendido entre 1851 e 1992, as autoras acabam involuntariamente fornecendo elementos para a percepção de permanências importantes. Dizem, por exemplo, que as exposições do século XIX eram mercados de vendas comerciais enquanto que após 1930 a venda permanece mas muda o produto, que passa a ser "os gêneros de vida, ligados a representações nacionais atrativas, a construções políticas e ideológicas de que se vendem os méritos ou as visões da sociedade futura idealizada pelos usos da ciência e da técrica" (p.6). Ora, não foi sempre assim? Parece-nos pensar que as exposições do século XIX vendessem apenas produtos, quando aquilo que se vendia, primordialmente, era a idéia da 
sociedade industrial, do progresso material como caminho de felicidade, no qual todos se deveriam congraçar, em harmonia universal. $O$ que se vendia era - sim - um gênero de vida, uma construção política e ideológica e visões de uma sociedade futura idealizada, mesmo que "os organizadores das exposições dos anos 30 sublinhem os fundamentos culturais e científicos de suas exposiçōes, a necessidade de torná-las didáticas, e as oponham às manifestações mercantis de outrora, as feiras de vocação comercial do século XIX" (Rasmussen, p. 35).

É verdade que a exposição de 1851 nasceu - e nisto foi seguida pelas demais do século XIX - com o caráter primeiro daquilo que chamamos de feira industrial (exibição e comércio de produtos) mas imediatamente as exposições excederam este objetivo para se mostrarem como representações do mundo. Apenas que, naquele período, a grande chave que se propunha para $\circ$ mundo era justamente a industrialização. E foi isto, na verdade, o que mudou: com a descrença na ideologia do progresso, mudou a proposta de mundo mas não se pode dizer que o que se vendia antes não fosse um mundo ou um modo de vida. Ao contrário.

Assim também, em outro momento, Rasmussen explica que a Exposição de 1992 (Sevilha) organiza-se em "quatro pavilhões temáticos, de apresentação completamente abstrata la visão da história, o conceito do futuro, a capacidade imaginativa do homem) e de produção cultural (arquitetura, design, ciência, tecnologia, artes, espetáculos) dentro do respeito aos quadros nacionais expressos pelos pavilhōes. $O$ projeto de classificação da exposição universal - continua a autora - testemunha bem a evolução dos objetos de exposição: passou-se do industrial ao cultural, da exposição de produtos à exposição de Conceitos" (Rasmussen, p.37). Mas não foi sempre assim? A indústria e a produção em escala não eram o eixo de um conceito de sociedade e cultura? É verdade que em sua positivação (regulamentação) as classificações previstas mudaram bastante mas não as significações, a nosso ver: o que eram as exposições retrospectivas (como a do trabalho ou a da habitação, montadas com tanta ênfase na Exposição de 1889), senão representações de uma visão histórica, conceitual? $\bigcirc$ que eram as exibições dos inventos mais recentes, como a locomotiva (1851) ou o telefone (1876), senão a demonstração da capacidade criativa do homem? $\bigcirc$ que era o significado de toda uma exposição, como panorama evolutivo do progresso lo passado, nas exposiç̃es retrospectivas, evoluindo até o genialidade das invenções e da indústria de então), senão uma promessa -e um projeto - de futuro? E o que eram, ainda, os próprios palácios, pavilhões, jardins e monumentos construídos para as exposições, os espetáculos de música e dança e as variedades gastronômicas, senão correspondentes de nosso conceito de produtos e eventos culturais?

Sem dúvida alguma as exposições universais surgidas no século XIX ligam-se à mentalidade cientificista e daí aos sistemas classificatórios enciclopédicos que as organizam, como demonstrado por Rasmussen, no capítulo dedicado à questão. Esta mentalidade transparece, ou melhor, é declarada, seja nos discursos de intençães, nas exposições de motivos, nas crônicas ou nos relatórios que se produziram. 
As exposições são sistemas de representação nos quais a classificação (associada à comparação) tem um papel determinante. Embora sendo uma constatação aparentemente simples, parece nunca ter sido definida e estudada com a clareza com que o fez Anne Rasmussen. Indicando as origens da classificação no naturalismo do século XVIII, mostra todas as mudanças significativas que vão ocorrendo de uma exposição para outra.

Do ponto de vista museológico cumpre ressaltar um tópico: a relação que Rasmussen faz entre a classificação e a organização do espaço constitui-se em contribuição original e preciosa para a compreensão das exposições enquanto realizações, por assim dizer, museológicas. A autora refere-se ao projeto de Le Play e suas implicações para a organização da Exposição Universal de 1867: trata-se de uma "reflexão de tipo filosófico, de visão enciclopédica, que tem como ambição enquadrar o conjunto, não só da produção industrial, mas de tudo o que é próprio à atividade humana (...) tudo mostrar e num só espaço, seguindo o princípio da legibilidade e, portanto, do didatismo" (Rasmussen, p. 24).

Vê-se, então, que em 1867 (Paris) é estabelecido, pela primeira vez, um projeto, que se poderia chamar de museográfico: conjuga-se, pelo projeto de Le Play, uma organização visual com a concepção intelectual da Exposição, baseada em um tipo de classificação que pretende catalogar todas as atividades humanas.

Como vimos acima, Rasmussen trabalha as classificações em seu sentido de divisões regulamentares existentes para determinadas partes das exposições. Isto por si só é já campo para uma longa pesquisa, cuja problemática principal a autora é a primeira a apresentar: as modificações nos sistemas classificatórios que ocorrem de uma exposição para outra, de acordo com o contexto histórico em que se realizam, isto é, de acordo com o período em que se dão e conforme os padrões intelectuais e as linhas filosóficas adotadas pelo grupo organizador, ligados a espécies de "estilos nacionais" que se quer afirmar.

Mas em outra perspectiva, pensamos que a idéia de uma organização espacial (museografia) correspondente a uma dada concepção intelectual e ideológica (museologia), possa ser aplicada ao conjunto de cada exposição e não somente às partes em que se obedecia o disposto em uma regulamentação escrita. Pavilhões nacionais, municipais, alguns pavithões temáticos, exposições retrospectivas, exposições coloniais e outras partes não eram objeto de regulamentação classificatória nos termos dos produtos industriais; nem por isto deixavam de corresponder a um certo tipo de classificação. Se na museografia inaugurada em 1867, "como entre os naturalistas, o lugar ocupado determina o papel representado no conjunto da atividade humana" (Rasmussen, p. 26), como se estabelecia o papel das nações? Afinal, embora as nações não submetam seus respectivos pavilhões às classificações regulamentares dedicadas às seções industriais, elas têm presença física marcada nos mesmos, circuitos espaciais que constituem, em seu todo, cada exposição universal. É neste sentido que pensamos ser possivel falar nas exposições como maquetes do mundo. Pois no contexto positivista em que se dão as exposições do século XIX, o conjunto 
de atividades, realizações concretas e progressos palpáveis é o que se entende como sendo o próprio mundo - ou ao menos o mundo desejado e pregado.

Parece-nos que Schroeder-Gudehus e Rasmussen atingiram plenamente o objetivo de sua obra, fornecendo de um lado dados precisos sobre cada exposição - o que facilita enormemente o trabalho do pesquisador - e de outro lado esboçando as principais questões que tocam o tema das exposições universais. A obra é, assim, a um tempo referência para consultas e estímulo para o debate de idéias. 